\title{
CLASSIFICAÇÃO DAS CEFALÉIAS
}

\author{
CLASSIFICATION FOR HEADACHE DISORDERS
}

José Geraldo Speciali

Docente do Departamento de Neurologia, Psiquiatria e Psicologia Médica da Faculdade de Medicina da Universidade São Paulo. CoRRESPONDÊnCIA: Prof.Dr. José Geraldo Speciali - Departamento de Neurologia, Psiquiatria e Psicologia Médica do Hospital das Clínicas da FMRP-USP - Campus Universitário - Ribeirão Preto - CEP: 14048-900.

\section{SPECIALI JG. Classificação das cefaléias. Medicina, Ribeirão Preto, 30: 421-427, out./dez. 1997.}

RESUMO: A classificação das cefaléias, proposta pela Sociedade Internacional de Cefaléias, em 1988, é discutida e criticada em seus vários aspectos. Além da importância científica, da uniformização de nomenclatura, esta classificação tem importância clínica, para o diagnóstico, prognóstico e terapêutica das cefaléias.

UNITERMOS: Cefaléia; classificação.

Cefaléia é um sintoma muito freqüente e deve ser considerado um sinal de alerta, seja ela conseqüência de problemas graves ou não. A classificação das cefaléias tem utilidade clínica, auxiliando no estabelecimento do diagnóstico, prognóstico e abordagem em terapêutica, e científica, uniformizando a nomenclatura dos diversos tipos de cefaléia, estudados em diferentes centros de investigação.

\section{CRITÉRIOS DE CLASSIFICAÇÃO}

Podemos classificar as cefaléias de varias maneiras.

\section{1 . Segundo a etiologia}

a) Cefaléias primárias: são as que ocorrem sem etiologia demonstrável pelos exames clínicos ou laboratoriais usuais. O principal exemplo é a migrânea (enxaqueca), a cefaléia tipo tensão, a cefaléia em salvas e outras. Nestes casos, desordens neuroquímicas, encefálicas têm sido demonstradas, envolvendo desequilíbrio de neurotransmissores, principalmente para a migrânea. Tais desordens seriam herdadas e, sobre tal susceptibilidade endógena, atuariam fatores ambientais. b) Cefaléias secundárias: são as provocadas por doenças demonstráveis pelos exames clínicos ou laboratoriais. Nestes casos, a dor seria conseqüência de uma agressão ao organismo, de ordem geral ou neurológica. Citamos, como exemplo, as cefaléias associadas às infecções sistêmicas, disfunções endócrinas, intoxicações, ainda à hemorragia cerebral, às meningites, encefalites ou a lesões expansivas do SNC.

Após o atendimento de um paciente com cefaléia, o médico deve estar seguro para optar entre o diagnóstico de cefaléia primária ou secundária. Os exames subsidiários deverão ser solicitados, quando há impossibilidade de certeza diagnóstica de cefaléia primaria.

\subsection{Segundo o modo de instalação e a evolução}

a) Cefaléias explosivas: são as que surgem abruptamente, em fração de segundo, atingindo a intensidade máxima instantaneamente, às vezes, com o paciente se referindo a um estalo. Esta instalação sugere a ruptura de um aneurisma arterial intracraniano ou de outras malfomações vasculares. Existem, no entanto, tipos benignos de cefaléia que podem ter início dessa forma, a cefaléia orgásmica e a "thunderclap headache". 
b) Cefaléias agudas: são as que atingem seu máximo em minutos ou poucas horas. Tanto as cefaléias primárias como as secundárias podem apresentar este tipo de instalação. Citamos, como exemplos, a migrânea, cefaléia de tensão, meningites, encefalites, hemorragias cerebrais não arteriais, sinusites agudas.

c) Cefaléias subagudas: instalação insidiosa, atingindo o ápice em dias ou poucos meses (até três meses). Ocorrem, principalmente, nas cefaléias secundárias, decorrentes de hematomas subdurais, tumores de crescimento rápido, meningites crônicas (fungo, tuberculose).

d) Cefaléias crônicas: são as que persistem por meses ou anos e, em geral, são primárias. Podem ser recidivantes, ocorrendo por período variável de tempo (minutos, horas, dias) para depois desaparecerem, reaparecendo algum tempo depois, como a migrânea, cefaléia em salvas, cefaléia tipo tensão esporádica e outras. Podem ser persistentes, aparecendo diariamente ou quase diariamente, por um período mínimo de quatro horas. A intensidade da dor deve permanecer mais ou menos a mesma no decorrer dos meses. São estas as características da cefaléia crônica diária, uma das que mais aparecem em consultórios médicos, especializados em cefaléia. O médico deve estar atento, nas cefaléias crônicas, para mudanças das características ou da intensidade da dor, pois podem indicar o aparecimento de cefaléia secundária associada.

\subsection{Segundo a Sociedade Internacional de Cefaléia}

A partir da década de 60 , houve um grande avanço no estudo das cefaléias. As definições dos vários tipos de migrânea, das cefaléias tipo tensão e de outras obedeciam critérios não universais, dificultando a comparação de resultados entre os vários centros de pesquisa.

Em 1988, a Sociedade Internacional de Cefaléia publicou a "Classificação e Critérios Diagnósticos das Cefaléias, Nevralgias Cranianas e Dor Facial". Esta classificação procurou correlacionar as várias etiologias com tipos específicos de dor de cabeça e procurou estabelecer critérios diagnósticos operacionais restritivos para as cefaléias primárias. Introduziu, também, a noção de níveis de diagnóstico. Atualmente, esta classificação é aceita pelos principais centros de estudo e qualquer trabalho científico a respeito de cefaléia dificilmente será publicado, se não estiver de acordo com a classificação proposta.

\section{MigrâneA}

1.1 Migrânea sem aura

1.2 Migrânea com aura

1.2.1 Migrânea com aura típica

1.2.2 Migrânea com aura prolongada

1.2.3 Migrânea hemiplégica familial

1.2.4 Migrânea basilar

1.2.5 Aura de migrânea sem cefaléia

1.2.6 Migrânea com aura de instalação aguda

1.3 Migrânea oftalmoplégica

1.4 Migrânea retiniana

1.5 Síndromes periódicas da infância que podem ser precursoras de, ou estarem associadas a migrânea 1.5.1 Vertigem paroxística benigna da infância

1.5.2 Hemiplegia alternante da infância

1.6 Complicações da migrânea

\subsubsection{Estado migranoso}

1.6.2 Infarto migranoso

1.7 Distúrbio migranoso, que não preencha os critérios acima

\section{Ceffaléia do tipo tensional}

2.1 Cefaléia do tipo tensional, episódica

2.1.1 Cefaléia do tipo tensional, episódica, associada a distúrbio de músculos pericranianos

2.1.2 Cefaléia do tipo tensional, episódica, não associada a distúrbio de músculos pericranianos

2.2 Cefaléia do tipo tensional, crônica

2.2.1 Cefaléia do tipo tensional, crônica, associada a distúrbio de músculos pericranianos

2.2.2 Cefaléia do tipo tensional, crônica, não associada a distúrbio de músculos pericranianos

2.3 Cefaléia do tipo tensional, que não preencha os critérios acima

\section{Cefaléia em salvas e hemicrania paroxística CRÔNICA}

3.1 Cefaléia em salvas

3.1.1 Cefaléia em salvas, de periodicidade não determinada

3.1.2 Cefaléia em salvas, episódica

3.1.3 Cefaléia em salvas, crônica

3.1.3.1 Sem remissões desde o início

3.1.3.2. Proveniente de episódica 
3.2 Hemicrania paroxística crônica

3.3 Distúrbio semelhante à cafaléia em salvas, que não preenche os critérios acima

4. Cefaléias diversas, não associadas a lesão esTRUTURAL

4.1 Cefaléia idiopática em facada

4.2 Cefaléia por compressão externa

4.3 Cefaléia por estímulo frio

4.3.1 Aplicação externa de um estimulo frio

4.3.2 Ingestão de um estimulo frio

4.4 Cefaléia benigna da tosse

4.5 Cefaléia benigna do esforço

4.6 Cefaléia associada a atividade sexual

4.6.1 Tipo peso

4.6.2 Tipo explosivo

4.6.3 Tipo postural

\section{Cefaléia associada a traumatismo craniano}

5.1 Cefaléia pós-traumática aguda

5.1.1 Com trauma craniano grave e/ou sinais comprobatórios

5.1.2 Com trauma craniano leve e sem sinais comprobatórios

5.2 Cefaléia pós-traumática crônica

5.2.1 Com trauma craniano grave e/ou sinais comprobatórios

5.2.2 Com trauma craniano leve e sem sinais comprobatórios

\section{Cefaléia associada a distúrbios vasculares}

6.1 Doença cerebrovascular isquêmica aguda

6.1.1 Ataque isquêmico transitório (TIA)

6.1.2 Icto tromboembólico

6.2 Hematoma intracraniano

6.2.1 Hematoma intracerebral

6.2.2 Hematoma subdural

6.2.3 Hematoma epidural

6.3 Hemorragia subaracnóidea

6.4 Malformação vascular não rota

6.4.1 Malformação arteriovenosa

6.4.2 Aneurisma sacular
6.5 Arterite

6.5.1 Arterite de células gigantes

6.5.2 Outras arterites sistêmicas

6.5.3 Arterite intracraniana primária

6.6 Dor das artérias carótida e vertebral

6.6.1 Dissecção de carótida ou de vertebral

6.6.2 Carotidinia (idiopática)

6.6.3 Cefaléia pós-endarterectomia

6.7 Trombose venosa

6.8 Hipertensão arterial

6.8.1 Resposta pressórica aguda a agente exógeno

6.8.2 Feocromocitoma

6.8.3 Hipertensão maligna (acelerada)

6.8.4 Pré-eclampsia e eclampsia

6.9 Cefaléia associada a outro distúrbio vascular

7. Cefaléia associada a distúrbio intracraniano, NÃO VASCULAR

7.1 Pressão liquórica elevada

7.1.1 Hipertensão intracraniana, benigna

7.1.2 Hidrocefalia de pressão elevada

7.2 Pressão liquórica baixa

7.2.1 Cefaléia pós-punção lombar

7.2.2 Cefaléia por fístula liquórica

7.3 Infecção intracraniana

7.4 Sarcoidose intracraniana e outras doenças inflamatórias não infecciosas

7.5 Cefaléia associada a outro distúrbio intracraniano

7.6 Neoplasia intracraniana

7.7 Cefaléia associada a outro distúrbio intracraniano

8. Cefaléia associada ao uso de substâncias ou à SUA SUPRESSÃo

8.1 Cefaléia induzida pelo uso ou exposição aguda a uma substância

8.1.1 Cefaléia induzida por nitrato/nitrito

8.1.2 Cefaléia induzida por glutamato monossódico

8.1.3 Cefaléia induzida por monóxido de carbono

8.1.4 Cefaléia induzida por álcool

8.1.5 Outras substâncias 
8.2 Cefaléia induzida pelo uso ou exposição crônica a uma substância

8.2.1 Cefaléia induzida por ergotamina

8.2.2 Cefaléia por abuso de analgésicos

8.2.3 Outras substâncias

8.3 Cefaléia por supressão de uma substância (uso agudo)

8.3.1 Cefaléia por supressão de álcool (ressaca) 8.3.2 Outras substâncias

8.4 Cefaléia por supressão de uma substância (uso crônico)

8.4.1 Cefaléia por supressão de ergotamina

8.4.2 Cefaléia por supressão de cafeína

8.4.3 Cefaléia por abstinência de narcóticos

8.5 Cefaléia associada a substâncias, com mecanismo incerto

8.5.1 Púlulas anticoncepcionais ou estrógenos

8.5.2 Outras substâncias

\section{Cefaléia associada a infecção não cefálica}

9.1 Infecção virótica

9.1.1 Não cefálica focal

9.1.2 Sistêmica

9.2 Infecção bacteriana

9.2.1 Não cefálica focal

9.2.2 Sistêmica (septicemia)

9.3 Cefaléia relacionada a outra infecção

\section{Cefaléia associada a distúrbio metabólico}

10.1 Hipóxia

10.1.1 Cefaléia das alturas

10.1.2 Cefaléia da hipóxia

10.1.3 Cefaléia da apnéia do sono

10.2 Hipercapnia

10.3 Associação de hipóxia e hipercapnia

10.4 Hipoglicemia

10.5 Diálise

10.6 Cefaléia relacionada a outra anormalidade metabólica

11. Cefaléta ou dor facial, associada a distúrbio DE CRÂNIO, PESCOÇO, OLHOS, OUVIDOS, NARIZ, SEIOS DA FACE, DENTES, BOCA OU A OUTRAS ESTRUTURAS DA FACE OU CRÂNIO

11.1 Osso craniano
11.2 Pescoço

11.2.1 Coluna cervical

11.2.2 Tendinite retrofaríngea

11.3 Olhos

11.3.1 Glaucoma agudo

11.3.2 Erros de refração

11.3.3 Heteroforia ou heterotropia

11.4 Ouvidos

11.5 Nariz e seios da face

11.5.1 Cefaléia sinusal aguda

11.5.2 Outras doenças do nariz ou dos seios da face

11.6 Dentes, mandíbulas e estruturas correlatas

11.7 Doença da articulação temporomandibular

12. NeVRalgias Cranianas, dor de tronco nervoso E DOR NA DESAFERENTAÇÃO

12.1 Dor persistente (contrastando com a dor da nevralgia do trigêmeo) originada de nervo craniano 12.1.1 Compressão ou distorção de nervos cranianos e das segundas ou terceiras raízes cervicais

12.1.2 Desmielinização de nervos cranianos

12.1.2.1 Neurite óptica (neurite retrobulbar)

12.1.3 Infarto de nervos cranianos

12.1.3.1 Neurite diabética

12.1.4 Inflamação de nervos cranianos

12.1.4.1 Herpes Zoster

12.1.4.2 Nevralgia pós-herpética crônica

12.1.5 Síndrome de Tolosa-Hunt

12.1.6 Síndrome pescoço-língua

12.1.7 Outras causas de dor persistente com origem em nervo craniano

12.2 Nevralgia do trigêmeo

12.2.1 Nevralgia idiopática do trigêmeo

12.2.2 Nevralgia sintomática do trigêmeo

12.2.2.1 Compressão da raiz ou do gânglio do trigêmeo

12.2.2.2 Lesões centrais

12.3 Nevralgia do glossofaríngeo

12.3.1 Nevralgia idiopática do glossofaríngeo

12.3.2 Nevralgia sintomática do glossofaríngeo

12.4 Nevralgia do intermédio 
12.5 Nevralgia do laríngeo superior

12.6 Nevralgia occipital

12.7 Causas centrais de dor cefálica e facial, outras que não a nevralgia do trigêmeo

12.7.1 Anestesia dolorosa

12.7.2 Dor talâmica

12.8 Dor facial que não preencha os critérios dos grupos 11 ou 12

\section{Cefaléía não classificável}

\section{COMENTÁRIOS À CLASSIFICAÇÃO DA SIC}

Nível de diagnóstico: é dado pelo número de dígitos utilizado no diagnóstico. É recomendável que todos os médicos conheçam a classificação até, no mínimo, o nível de dois dígitos. Em pesquisa, todos os níveis de diagnóstico devem ser utilizados.

Mais de um diagnóstico: muitos pacientes têm mais de um tipo de cefaléia. Nesses casos, devemos incluir todos os diagnósticos; por exemplo, migrânea, e cefaléia tipo tensão.

Ao se tratar de migrânea, o nível diagnóstico de dois dígitos é o esperado: migrânea com aura (1.2), sem aura (1.1), etc. Ao acrescentarmos mais um dígito ao diagnóstico 1.2., estaremos qualificando melhor o tipo de aura. Por exemplo, 1.2.6. indica que a aura se instalou em menos de cinco minutos.

A classificação das migrâneas em 1.3., Migrânea oftalmoplégica, 1.4. Migrânea retiniana, 1.5. Síndromes periódicas da infância, que podem ser precursoras ou estar associadas a migrânea, e 1.6. Complicações da migrânea, requer conhecimentos mais aprofundados. É necessário lembrar que a migrânea, mesmo benigna, pode ter complicações graves, tais como o infarto cerebral migranoso, e o estado de mal migranoso, e que crises vertiginosas e hemiplegia alternante, em crianças, podem ser manifestações clínicas precursoras ou acompanhantes da migrânea.

O nível diagnóstico de dois dígitos para a cefaléia tipo tensão (CTT) também é fácil, e deve ser utilizado de rotina: CTT esporádica (2.1) e CTT crônica (2.2). Como não há consenso para a avaliação de distúrbios da musculatura pericrânica, o diagnóstico em nível de três dígitos permanece subjetivo. Um quarto dígito pode ser colocado, quando a causa da cefaléia tipo tensão é conhecida. Por exemplo, se a causa de uma cefaléia tipo tensão esporádica for depressão e não conseguimos saber se há ou não distúrbio da musculatura pericrânica, devemos classificá-la como
2.1.0.5. As principais causas de cefaléia tipo tensão reconhecidas pela classificação são: disfunção oromandibular (2), estresse psicossocial (3), ansiedade (4), depressão (5), cefaléia como uma ilusão ou idéia (6), estresse muscular (7), abuso de drogas (8).

O item 3 da classificação refere-se a cefaléias unilaterais: cefaléia em salvas (CS) e hemicrania paroxística crônica (HPC). Ocorrem sempre de um só lado da cabeça e só excepcionalmente mudam de lado, diferindo portanto da migrânea. Além desta peculiaridade, são dores de curta duração (até cento e oitenta minutos para a CS e até quarenta e cinco minutos para a HPC). A intensidade da dor é excruciante (principalmente na CS) e ocorrem, principalmente, durante o sono (principalmente a CS). São acompanhadas por fenômenos autonômicos do lado da dor (miose, ptose palpebral, coriza, lacrimejamento, congestão conjuntival) e têm respostas específicas a medicações (Sumatriptam e O2 para a CS e Indometacina para a HPC). O diagnóstico diferencial entre esses dois tipos de cefaléia se faz, principalmente, pelo número de crises diárias uma a três para a CS e mais de cinco na HPC, duração da dor e resposta às medicações específicas.

As crises de dor, nas duas variedades, podem aparecer agrupadas, em salvas, ocorrendo por um a dois meses, a cada seis ou mais meses (forma episódica). Na forma crônica, as crises álgicas ocorrem diariamente ou quase diariamente, por meses ou anos.

O item 4 da classificação refere-se também a cefaléias primárias. $\mathrm{O}$ diagnóstico em dois dígitos é necessário. $\mathrm{O}$ segundo dígito refere-se ao tipo de cefaléia (4.1) ou aos fatores desencadeantes (4.2 a 4.6).

A cefaléia idiopática em facadas é caracterizada por dores de cabeça fugazes, de poucos segundos de duração, em pontadas, facadas, alfinetadas, podendo ser únicas ou agrupadas em surtos de poucos minutos. Podem repetir ou não no decorrer do dia. Muitas vezes são diárias, mas podem aparecer em intervalos de tempo variáveis, de dias a meses. Ocorrem, preferentemente, na região do primeiro ramo do trigêmeo, sendo comum em pessoas com migrânea.

As cefaléias dos itens 4.2 e 4.3 dispensam comentários.

As cefaléias classificadas em 4.4., 4.5. e 4.6. são desencadeadas por esforço. Nestes casos, impõe-se o diagnóstico diferencial com cefaléia secundária, relacionada a rompimento de malformações vasculares cerebrais. Em geral, são necessários exames subsidiários.

Os itens de 1 a 4 referem-se às cefaléias primárias. Os itens de 5 a 11 correspondem, salvo poucas 
exceções, às cefaléias secundárias. As características da dor raramente sugerem a etiologia ou são critério diagnóstico de uma cefaléia secundária. Em geral, as cefaléias secundárias dão como manifestação clínica sintomas de migrânea, cefaléia tipo tensão ou outro tipo de cefaléia primária. São os sinais/sintomas associados que alertarão o médico experiente para a necessidade de exames subsidiários.

Os pacientes que apresentarem um tipo particular de cefaléia, bem relacionada, no tempo, com a ocorrência de uma das causas arroladas nos grupos 5-11, serão codificados em um daqueles grupos. Se o paciente, antes do evento, apresentar algum tipo de cefaléia e, após, houver piora dos sintomas, o diagnóstico será o de antes. Por exemplo, se houver piora dos sintomas de migrânea após trauma craniano, o diagnóstico continua o de migrânea.

\section{CEFALÉIAS SECUNDÁRIAS}

Descreveremos algumas cefaléias secundárias com sinais/sintomas que auxiliam o diagnóstico etiológico:

\subsection{Hemorragia subaracnóidea}

Início explosivo

Dor severa, holocraniana

Não melhora com analgésicos

Sinais neurológicos (rigidez nucal, hemiparesia, assimetria de reflexos, outros)

Hipertermia

\subsubsection{Arterite de células gigantes}

Dor em artérias do couro cabeludo, usualmente artéria temporal superficial

Claudicação nos masseteres, com dor desencadeada pela mastigação

Dolorimento e inflamação palpável das artérias comprometidas, VHS aumentado

\subsubsection{Carotidinia (idiopática)}

Dor, edema e/ou pulsações aumentadas na artéria carótida, unilateral

A investigação descarta anormalidade do tipo dissecção

Autolimitada, desaparecendo em até duas semanas.

\subsubsection{Feocromocitoma}

Cefaléia com aumento da pressão sangüínea, de curta duração, holocraniana

Sudorese, palpitação e/ou ansiedade.
7.2. Pressão liquórica baixa

Cefaléia bilateral

Aparece ou se agrava, em menos de quinze minutos, após assumir a posição ortostática

Desaparece ou melhora muito, em menos de trinta minutos, após assumir a posição deitada

Quando associada à punção liquórica desaparece quinze dias após o procedimento

Quando não associada à punção, considerar a possibilidade de fístula liquórica

\subsubsection{Cefaléia induzida por glutamato monos- sódico}

Cefaléia surgindo até uma hora após ingestão de glutamato monossódico

Associada com pressão no tórax, aperto na face, queimação no tórax, pescoço e ombros e rubor facial

Tonturas

Desconforto abdominal

\subsubsection{Cefaléia induzida por ergotamina}

Associada à ingestão crônica diária de ergotamina (oral $>2 \mathrm{mg}$ )

Difusa, pulsátil, diária, piorando nos dias subseqüentes à suspensão da droga

\subsubsection{Cefaléia por abuso de analgésicos}

Associada ao uso de aspirina ( $>50 \mathrm{~g}$ ao mês)

Associada ao uso de analgésicos (> 100 comp. ao mês)

Paciente com história de cefaléia primária prévia

11.2.1. Cefaléia de origem cervical

Dor localizada no pescoço e região occipital. Pode projetar-se para a fronte, região orbitaria, têmporas, "vertex" ou ouvidos

Dor precipitada ou agravada por movimentos ou posturas persistentes do pescoço

Resistência à movimentação passiva do pescoço, alterações da musculatura do pescoço (relevo, textura, tono) ou dolorimento anormal dessa musculatura

Alterações no exame radiológico da coluna cervical (nos movimentos, na postura ou outras que não espondilose e osteocondrose)

\subsection{Doença da articulação temporomandibular}

Dor localizada na região temporomandibular

Dor na mandíbula, nos movimentos ou no cerrar os dentes

Diminuição na amplitude de abertura da boca

Ruído durante os movimentos da articulação

Alterações nas radiografias ou cintilografias das articulações. 
$\mathrm{O}$ item 12 relativo às Nevralgias, dor de troncos nervosos e dor de desaferentação e o item 13 (cefaléia não classificável) assim como cefaléias não correspondentes da classificação de IHS são comentados no Capítulo V.

\section{CONCLUSÕES}

Classificações, mesmo tediosas e, por vezes, até irritantes, são necessárias.

A classificação da SIC é extensa, mas não é necessário conhecê-la em todos os seus detalhes. Seu uso principal está relacionado à pesquisa, mas, com certeza, facilita nossos diagnósticos no atendimento a pacientes.

Classificar e definir doenças é sempre tarefa difícil e, no campo das cefaléias, apresenta problemas particulares. Não há exames de laboratório que possam ser utilizados como critérios diagnósticos, em qualquer das formas primárias de cefaléia. Existem síndromes típicas, mas, também, muitas formas de transição. Para o diagnóstico correto, a única informação para o médico é a referida pelo paciente, sendo importante saber ouvir e fazer perguntas objetivas no momento adequado.

A classificação atual desatualizou-se desde 1988. De lá para cá, algumas novas síndromes foram definidas e outras melhor compreendidas, como cefaléia crônica diária, SUNCT, cefaléia cervicogênica, dentre outras. Tal fato não indica falha da classificação atual, mas indica que o conhecimento das algias cranianas está se processando rapidamente como ocorre, aliás, em todas as áreas da Ciência.

SPECIALI JG. Classification for headache disorders. Medicina, Ribeirão Preto, 30: 421-427, oct./dec. 1997.

ABSTRACT: The classification of headache proposed by the International Society of Headaches in 1988 is discussed and criticized in various aspects. Revides scientific relevance of nomenclature uniformization, this classification is important for diagnosis, prognosis and therapy of headache.

UNITERMOS: Headache; classification.

\section{BIBLIOGRAFIA CONSULTADA}

1 - HEADACHE CLASSIFICATION COMMITTEE OF THE INTERNATIONAL HEADACHE SOCIETY. Classification and diagnostic criteria for headache disorders, cranial neuralgias and facial pain. Cephalalgia 8: 1-96, 1988. Suppl. 7.
3 - SILVA WF. Cefaléias diagnostico e tratamento. Medsi Editora, Rio de Janeiro,1989.

Recebido para publicação em 05/11/97

Aprovado para publicação em 10/12/97

2 - OLESEN J; TFELT-HANSEN P \& WELCH KMA. The headaches. Raven Press, New York,1993. 